\title{
Double-blind crossover trial of oral meptazinol, pentazocine and placebo in the treatment of pain in the elderly
}

\author{
V. Pearce \\ M.B. B.S., M.R.C.P. \\ P. J. RoBSON \\ M.B. B.S., M.R.C.P. \\ Chesterton Hospital, Cambridge and Wyeth Laboratories, Maidenhead, Berkshire
}

\begin{abstract}
Summary
In a randomized, double-blind crossover trial in $\mathbf{3 0}$ elderly patients suffering from moderate to severe pain, the analgesic efficacy, tendency to produce mental confusion and side effect profile of meptazinol $100 \mathrm{mg}$ orally were compared with those of pentazocine $25 \mathrm{mg}$ orally and placebo.

Both the active drugs produced significantly better analgesia than placebo but meptazinol also provided significantly better pain relief than pentazocine, whilst at the same time causing less mental confusion. Side effects were unremarkable.

Meptazinol appears to be a better general purpose oral analgesic in this group of patients than pentazocine.
\end{abstract}

\section{Introduction}

It is commonly found that when it is necessary to use a strong analgesic such as an opiate or pentazocine in an elderly person there is a high incidence of adverse CNS effects such as confusion, agitation or hallucinations and these are clearly detrimental both to the patient and to the running of the ward.

Meptazinol is a novel benzomorphan compound with partial opiate-antagonist properties which has been shown to be equivalent in analgesic potency at a dose of $100 \mathrm{mg}$ to pethidine $100 \mathrm{mg}$ (Paymaster, 1977; A. Hedges (personal communication); M. B. A. Jackson and P. J. Robson (personal communication), papaveretum $20 \mathrm{mg}$ (Moyer, Miller and Aldridge, 1979) and pentazocine $60 \mathrm{mg}$ (Paymaster, 1977), all drugs given i.m. It is free from anti-5-hydroxytryptamine and anti-cholinergic activity and in clinical trial has shown a low incidence of CNS side effects. An additional factor in the group of patients is meptazinol's favourable respiratory profile (Jordan et al., 1979).

An open pilot study in 11 patients revealed that meptazinol $100 \mathrm{mg}$ orally gave satisfactory pain relief and was well tolerated, so it was therefore decided to compare the compound for efficacy and side effect incidence with the oral analgesic most frequently used for moderate to severe pain in the unit, pentazocine $25 \mathrm{mg}$ orally, and placebo. The $20 \mathrm{O}$ active drugs were given in deliberately small doses 3 as it is well recognized that age is highly correlated with the pain relief obtained from a given dose of analgesic (Bellville et al., 1971) and that the elderly of are more susceptible to drugs in general (Leading. Article, 1977).

\section{Materials and methods}

This was a randomized double-blind crossoverc trial in 30 patients over the age of 70 years who had given informed consent to participate and who $\overrightarrow{0}$ would in any case have required a potent oral an gesic. Eighteen patients were female, and the mean age was $81 \cdot 4 \pm 6 \cdot 4$ years.

TABLE 1. Painful conditions for which analgesia was required

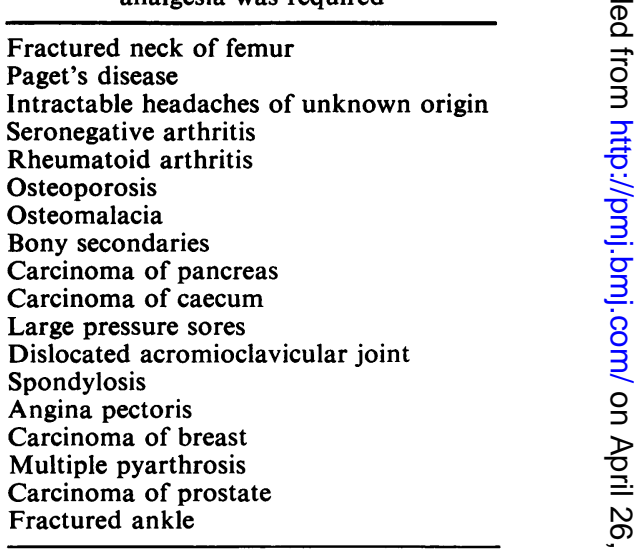

On admission to the study, all analgesics and non- N essential drugs were discontinued and each patiento was randomly allocated to either Group A, Group Bo or Group C. The painful conditions for which the patients required relief are shown in Table 1. Each $\stackrel{\text { ? }}{?}$ patient then received in random order placebo, $\overparen{D}$ meptazinol $100 \mathrm{mg}$ and pentazocine $25 \mathrm{mg}$ according to the following routine. 
On admission to the trial, and when an analgesic was requested by the patient, the pain intensity score was measured using a visual analogue scale, and the mental state assessed by the ' $E$ ' test. In this test, the patient is given a typewritten passage of writing which contains 50 letter ' $E$ 's, and is asked to read through the piece crossing out the 'E's, thereby obtaining a score out of 50. A different passage is used for each assessment, and it is generally accepted that performance in this test correlates well with the degree of mental confusion. Other observations made at this time included pulse rate, BP and the presence or absence of any other symptoms such as nausea and vomiting. Test drug no. 1 was then given, and the above observations repeated at 30 $\mathrm{min}$, one $\mathrm{hr}, 2 \mathrm{hr}$, and $4 \mathrm{hr}$. When next the patient requested an analgesic, an identical procedure was adopted for test drug 2 and likewise for test drug 3 . In the event of analgesia being inadequate during an observation period, the pain intensity for unmeasured time-points was adjudged as the maximum, 10, and the next test drug was given according to the randomized schedule. Blood samples for the measurement of meptazinol concentration in plasma were taken at the observation time-points from some patients in the trial.

\section{Results}

\section{Open pilot study}

Eleven patients suffering from moderate to severe pain of various aetiologies received $100 \mathrm{mg}$ meptazinol by mouth, and an ' $E$ ' test and pain intensity scored by visual analogue scale were measured at the following time-points; $0,30 \mathrm{~min}, 1,2,3$, and $4 \mathrm{hr}$. The mean results for the group are illustrated graphically in Fig. 1. Whereas mean pain intensity is significantly reduced from $30 \mathrm{~min}$ onwards $(P<0.025-W i l c o x o n$ matched pairs signed rank test), the fluctuations in ' $E$ ' score do not reach statistical significance.

\section{Double-blind study}

The pain intensity difference and ' $E$ ' scores are displayed graphically as group means in Figs 2 and 3. Pain intensity difference is obtained by subtracting the pain intensity at the various time-points from the pre-treatment pain intensity for each individual.

Both meptazinol and pentazocine gave significant pain relief at all times over the 4-hr period in comparison with placebo, and meptazinol gave significantly better pain relief than pentazocine at one and $2 \mathrm{hr}$ after dosing. At 3 and $4 \mathrm{hr}$, the pain relief afforded by the 2 active agents did not significantly differ.

Pentazocine depressed the ' $E$ ' score significantly more than meptazinol throughout the 4-hr period and indeed meptazinol differed from placebo in this regard at the 2-hr time-point only.

None of the test drugs had any significant effect on BP or pulse rate, and the side effect profile is shown in Table 2.

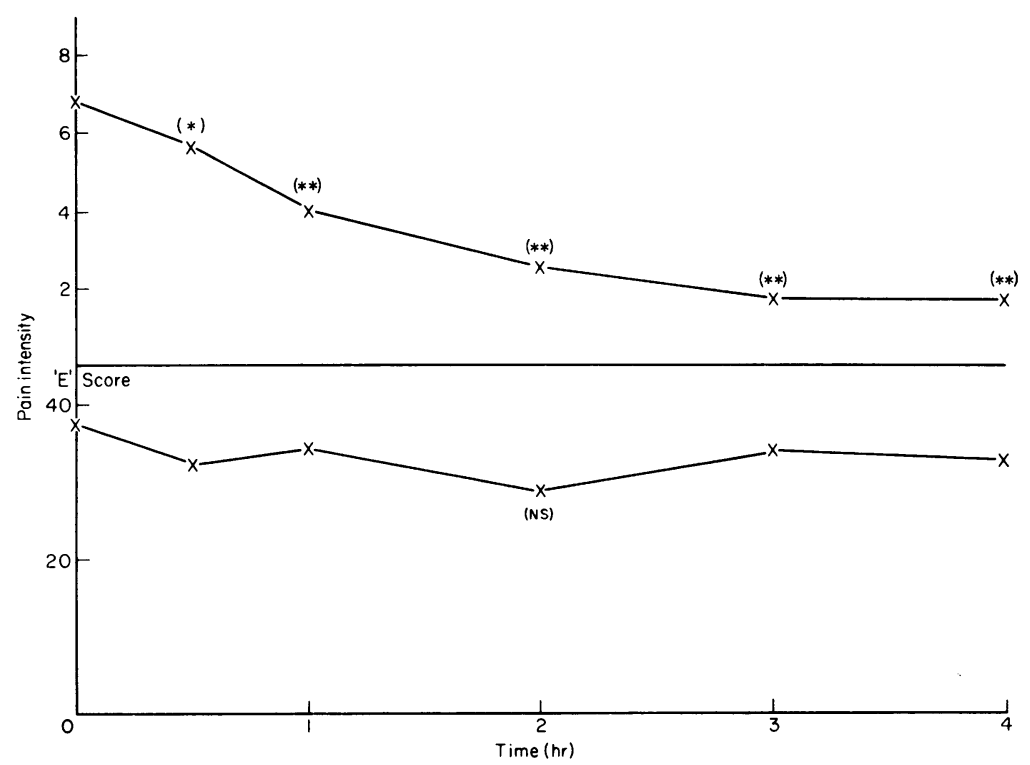

FIG. 1. Results of open pilot study. Comparison with base line. $\left({ }^{*}\right) P, 0.025 ;\left(^{* *}\right) P$, 0.005 ; (NS) not significant. 


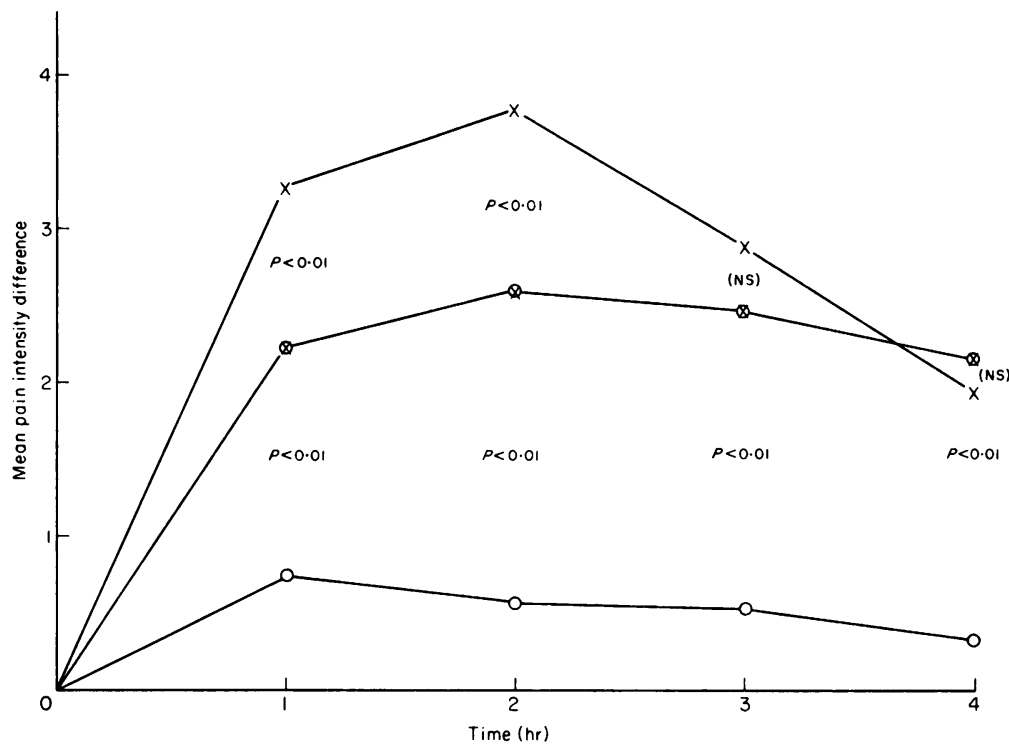

Fig. 2. Group mean pain intensity differences. $\times-\times$ metazinol $100 \mathrm{mg}$; $\otimes-\otimes$ pentazocine $25 \mathrm{mg} ; \bigcirc-\bigcirc$ placebo.

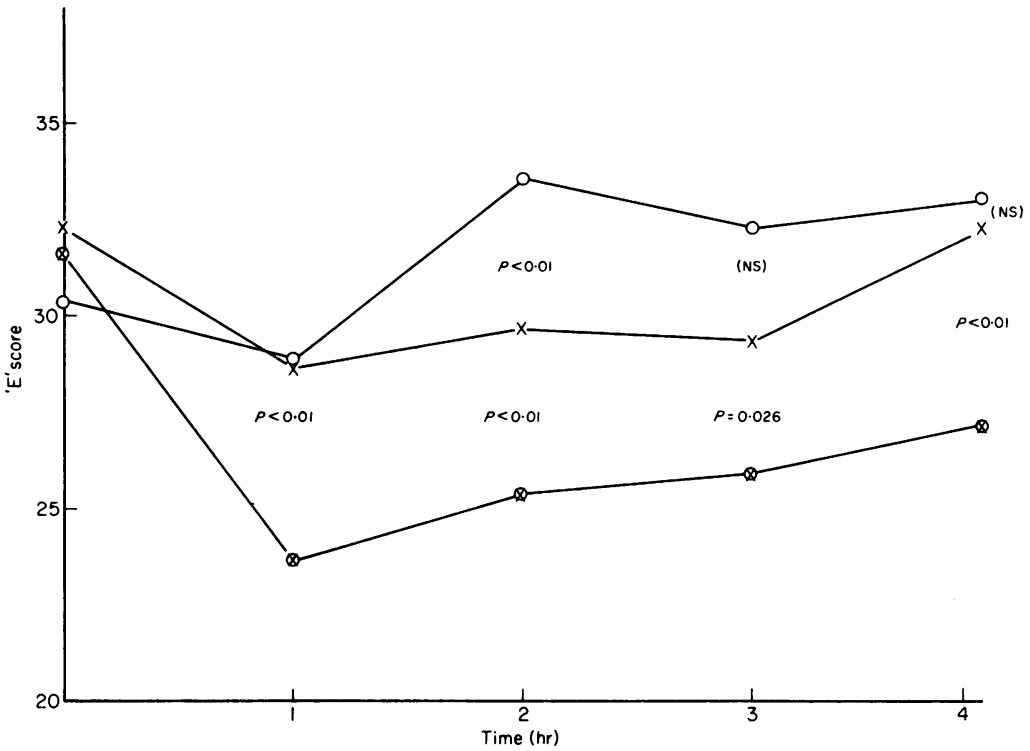

FIG. 3. Group mean 'e' scores.

TABLE 2. Side effects

\begin{tabular}{lccc}
\hline Side effect & Placebo & Meptazinol & Pentazocine \\
\hline Nausea and vomiting & 0 & 2 & 0 \\
Nausea alone & 0 & 1 & 1 \\
Dizziness & 1 & 0 & 0 \\
\hline
\end{tabular}


Peak plasma concentrations tended to occur at 2-3 hr after dosing, and the mean plasma concentration at this time in a group of 12 patients was $20 \cdot 1 \pm 17 \cdot 3$ (s.d.) $\mathrm{ng} / \mathrm{ml}$.

\section{Discussion}

Adverse reactions to drug therapy in the elderly are a major cause of morbidity. Important predisposing factors are age and sex; significantly more patients aged 60 years and over, and more women than men develop adverse reactions (Hurwitz, 1969).

Neurological and mental disturbances due to drug therapy are extremely common in the elderly, who are particularly susceptible to centrally acting drugs. The reactions seen include mental confusion, disorientation, hallucinations, fluctuating levels of awareness and depression (Davison, 1978). The elderly metabolize many drugs more slowly than do the young, and plasma half-lives for a given dose are prolonged (O'Mally et al., 1971).

The chief factors involved seem to be a reduced lean body mass and a substantial pre-existing impaired function of certain organs and systems, especially the central nervous, respiratory and cardiovascular systems, and the kidneys. In the case of potent analgesics, the elderly are prone to confusion and disorientation particularly if there is some prior erosion of mental reserve, and respiratory depression is a special hazard. Because gut transit times are often greatly prolonged in these patients, constipation is a frequent problem, and this is likely to be exacerbated by a number of analgesics.

Meptazinol has a favourable respiratory profile in comparison with morphine and pentazocine (Jordan et al., 1979; Verschraegen et al., 1976). Constipation has not been reported following its oral or parenteral administration in man. In animal studies, meptazinol caused less gastrointestinal inhibitory activity than equi-analgesic doses of morphine or pentazocine (Stephens, Waterfall and Franklin, 1978). As with other strong analgesics, meptazinol may induce nausea and vomiting, and this was seen in the study in low incidence, albeit more commonly than with pentazocine (Table 2).

In this group of patients meptazinol produced significantly better pain relief than did either pentazocine or placebo. Although the level of awareness as judged by the ' $E$ ' test was lower following meptazinol than that following placebo, it remained significantly superior to that following pentazocine for the entire period studied. No patient was noticeably confused or obtunded at the doses used.

In this group of very elderly patients in whom depression of awareness rapidly leads to deterioration of bladder control, diminution of mobility to pressure necrosis of skin, and constipation to discomfort and eventual overflow incontinence of faeces, the potential advantage of an effective analgesic agent attended by a diminished incidence of these problems is self-evident.

\section{Conclusion}

The present trial demonstrates that oral meptazinol offers advantages over pentazocine in the routine treatment of moderate to severe pain in the elderly.

The relief of pain by meptazinol as judged by a visual analogue scale was significantly better than that following pentazocine.

Awareness was significantly less impaired by meptazinol than by pentazocine.

\section{References}

Bellville, J.W., Forrest, W.H., Miller, E. \& Brown, B.W. (1971) Influence of age on pain relief from analgesics: A study of post-operative patients. Journal of the American Medical Association, 217, 1835.

DAvison, W. (1978) Neurological and mental disturbances due to drugs. Age and Ageing, 7 (Suppl.), 119.

Hurwitz, N. (1969) Predisposing factors in adverse reactions to drugs. British Medical Journal, 1, 536.

Jordan, C., Lehane, J.R., Robson, P.J. \& Jones, J.G. (1979) A comparison of the respiratory effects of meptazinol, pentazocine and morphine. British Journal of Anaesthesia, $51,497$.

Leading Article (1977) Drugs and the elderly. Lancet, ii, 693.

Moyer, D.G., Miller, M.T. \& Aldridge, N.J. (1979) A comparison between meptazinol and omnopon in the relief of post-operative pain. South African Medical Journal, (in press).

O'Malley, K., Crooks, J., Duke, E. \& Stevenson, I.H. (1971) Effect of age and sex on human drug metabolism. British Medical Journal, 3, 607.

Paymaster, N.J. (1977) Analgesia after operation: A controlled comparison of meptazinol, pentazocine and pethidine. British Journal of Anaesthesia, 49, 1139.

Stephens, R.J., Waterfall, J.F. \& Franklin, R.A. (1978) A review of the biological properties and metabolic disposition of the new analgesic agent, Meptazinol. General Pharmacology, 9, 73.

Verschraegen, R., Rosseel, M.Th., Bogaert, M. \& Rolly, G. (1976) Meptazinol: I.m. use in post-operative pain. Acta anaesthesiologica belgica, 27 (Suppl.), 123. 